\title{
SeX-Based Differences in Hamstring Injury Risk Factors
}

\author{
Lucy O’Sullivan, BS ${ }^{1}$, Miho J. Tanaka, MD, MA² \\ ${ }^{1}$ Johns Hopkins University School of Medicine, Baltimore, Maryland USA \\ ${ }^{2}$ Massachusetts General Hospital, Harvard Medical School, Boston, Massachusetts USA
}

\begin{abstract}
Hamstring injuries (HSI) are common in a number of different sports and can confer a significant burden to both male and female athletes. Though research on HSIs in the female athlete population is lacking, current literature suggests male athletes are between two to four times more likely than female athletes to sustain an HSI. Despite this discrepancy, the role of intrinsic sex differences in HSI risk factors has not been previously explored. This review aims to summarize these sex-based differences in HSI risk factors and their influence on the lower rate of HSIs seen in female athletes as compared to male athletes. Women exhibit increased hamstring flexibility and decreased hamstring musculotendinous stiffness as compared to men; women are also shown to be more resistant to skeletal muscle fatigue. Sex differences in the hamstring to quadriceps ratio and certain lower limb morphologies may also contribute to the sex discrepancy in HSI rates. This remains an area for future research in order to understand the multifaceted nature of HSI injury risk factors and optimize HSI rehabilitation and prevention programs for both male and female athletes.
\end{abstract}

\section{Introduction}

Hamstring injuries (HSIs), specifically hamstring myotendinous strain injuries, manifest as acute pain in the posterior thigh caused by disruption of the hamstring muscle fibers at the muscle-tendon junction ${ }^{1}$. This is in contrast to proximal hamstring tendinopathy, which is characterized by pain of the deep gluteal region². HSIs are also distinct from distal hamstring insertion injuries, such as semimembranosus tendinopathy, which can cause pain in the nnee $^{3}$. HSIs are one of the most common musculoskeletal injuries in sports, with an incidence that ranges between 0.3 to 4 injuries per 1000 hours of athlete exposure and a prevalence that is increasing by up to $4 \%$ annually ${ }^{4-6}$. Hamstring injuries are prevalent in sports that require intense bouts of high-speed running and/or kicking ${ }^{7-10}$. HSIs are particularly difficult for athletes to manage as they are associated with both a long duration away from sport as well as a high rate of re-injury ${ }^{11-14}$. Not only are athletes hindered by an excessive recovery time, but history of a previous HSI puts one at a substantially increased risk for re-injury. Athletes with a history of HSI are 2.7 times more likely to sustain another HSI than athletes without a previous history of one; this risk increases to 4.8 times more likely if the initial HSI has occurred within the past season ${ }^{14}$. The frequency, resulting time-off burden, and significant recurrence rate make HSIs an important focus of sports medicine research, and this research is a vital step in developing evidence-based approaches to prevention and recovery.

Few HSI studies include female participants and even fewer focus specifically on female athletes, even though studies suggest that hamstring injuries are a significant source of injury in this population. Female participation in sport has expanded drastically in the United States since the implementation of Title IX in 1972, and with increasing female engagement in sport comes an increasing rate of injuries in this population. Increased attention has been placed on studying sex-based differences that can cause women to exhibit unique patterns of injury compared to men $^{15}$. Emmonds et al have suggested that maledominated sports and exercise medicine research studies are inherently limited in scope and often poorly applicable to the female athlete population 
because of such differences ${ }^{16}$. Despite this, women continue to be significantly underrepresented in all sports and exercise medicine research studies ${ }^{17}$.

HSIs have been reported to be a prevalent problem in female athletes. In a study of female collegiate Gaelic football players, hamstring injuries were the most frequent injury recorded at $21.52 \%$ and lead to a burden of 66.12 days lost per 1000 hours, which was second only to knee injuries ${ }^{18}$. Other studies have found HSI to be the second most common injury amongst professional female soccer players, and the third most common among players at the amateur level ${ }^{19,20}$. Despite the significance of HSIs in both female and male athletics, the rates and risk factors of HSIs based on sex differences have not been previously described in the literature. The goal of this review is to present existing data on hamstring injuries in the context of the female athlete and compare these findings to what is already known about male HSIs. We also highlight the need for more evidence-based research that includes female participants, as well as consideration of sex-specific factors that may influence the prevalence, treatment, and prevention of HSI in female athletes.

\section{Hamstring Injury Rates in Female vs. Male Athletes}

Studies that directly compare HSI rates between male and female athletes reveal that male athletes are generally reported as being between two to four times more prone to HSIs than female athletes $6,21-25$. Injury data collected from NCAA soccer teams showed men were $64 \%$ more likely than women to sustain a hamstring strain. When comparing the risk of sustaining injury during games only, men were 2.42 times more likely21,22. Similarly, professional male soccer players have also been found to be at greater risk for HSI compared to professional female players; a 5-season comparison of elite male and female players from the same soccer club in the Spanish first division found HSIs were 1.93 times more frequent in men and accounted for a greater proportion of days lost due to injury 25 .

In the sport of track and field, men have been shown in several studies to have greater risk of HSI than women. Three years of HSI rates collected on over 48,000 athletes who participated in the Penn Relays Carnival from 2002-2004 showed men overall had $79 \%$ increased odds of suffering HSI compared with women ${ }^{6}$. However, the authors note this data is confounded by the greater number of male masters athletes and differences in event participation. When combining male and female data, the $100 \mathrm{~m}$ sprint, $110 \mathrm{~m}$ hurdles, and triple jump events, respectively, conferred the greatest relative risk of HSI, whereas the $4 \times 400 \mathrm{~m}$ relay had the highest absolute risk. Similarly, injury data from the Daegu 2011 IAAF World Championships and the 2007-2015 World Athletics Championships (WACs) showed male athletes suffered hamstring strains at a rate of two to four times greater than that of female athletes, with men being more likely to suffer time-loss from the sport due to injury 23,24 . Despite the increased reported rate and severity of HSI in male athletes, rates of HSIs based on each individual track and field event was not reported in either study ${ }^{23,24}$. This suggests that while studies overall report that men have greater rates of HSIs, little is known about the specific injury mechanisms and risk factors that are specific to women who sustain this injury.

\section{Sex Differences in HSI Risk Factors}

\section{Hamstring Length, Flexibility, and Extensibility}

The influence of hamstring flexibility on risk of sustaining an HSI is debated in the literature. Hamstrings are most susceptible to strain injuries during the terminal swing phase of sprinting when the muscle is eccentrically contracted and stretched passed its optimal length ${ }^{26}$. Wan et al. found athletes with less hamstring flexibility experienced greater peak muscle strain (the ratio of muscle length deformation to muscle optimal length) during this terminal swing phase of a sprint. The authors suggest that limited hamstring flexibility is a risk factor for HSIs, as greater strain imposed on the muscle during the terminal swing phase confers a greater chance of sustaining an injury ${ }^{26}$. This has been supported by several studies that have found a significant association between preseason hamstring muscle tightness and later development of a hamstring muscle injury, with Henderson et al. reporting every $1^{\circ}$ decrease in passive straight leg raise increased injury propensity by 1.29 times $^{27,28}$. Bradley and Portas also associated poor preseason hamstring flexibility in male soccer players with increased risk of sustaining an in-season HSI, in which flexibility was evaluated via the passive knee extension test ${ }^{29}$.

Women have been shown to have greater hamstring flexibility, as evidenced by greater 
muscle length, stretch tolerance, and hamstring extensibility than men ${ }^{30,31}$. Marshall and Siegler compared 45 men and 45 women using the instrumented Straight Leg Raise test and found hamstring extensibility was $9.9^{\circ}$ greater in women compared to men. The male and female subjects did not differ in age or participation rates in physical or stretching activities. In fact, 42 participants reported no regular physical activity at all, supporting the notion that greater hamstring extensibility in women may be an inherent physiological property that is not dependent on athletic status ${ }^{30}$. Women also reported experiencing a significantly lower maximum pain intensity score during the instrumented Straight Leg Raise, suggesting they possess greater tolerance to stretching of the hamstring muscle $^{30}$. Similarly, Youdas et al. measured hamstring muscle length based on the passive straight leg raise and popliteal angle of over 200 adults aged 20-79. Women had greater measured hamstring muscle length than men using both methods of measurement (approximately $8^{\circ}$ greater passive straight leg raise and $11^{\circ}$ greater popliteal angle) ${ }^{31}$. However, the relationship between these findings and hamstring injuries in women has not yet been shown. Furthermore, the assessment of hamstring flexibility in studies is varied, using measures such as the active knee extension test, passive knee extension test, or sit and reach test, with many studies including only male subjects $^{32-37}$. Greater uniformity in the assessment of hamstring flexibility, as well as further study of the relationship between hamstring flexibility and injury risk in female athletes, is needed to determine the role of hamstring flexibility as a protective factor for HSI.

\section{Musculotendinous Stiffness}

Increased hamstring musculotendinous stiffness (MTS) has also been described as a potential risk factor for HSI. The intrinsic difference in female versus male MTS is an important factor to consider when discussing the discrepancy in HSI rates between these populations. MTS describes the ratio of change in force of a muscle to change in muscular length. A muscle with greater MTS requires a shorter change in muscle length to produce a given amount force compared to muscle with a lower MTS38. Wilson et al. was the first to propose that MTS may act as a greater risk factor than flexibility for musculotendinous soft-tissue injury ${ }^{39}$. A muscle with low MTS is able to extend to a greater length when perturbed by an external force; therefore, the force applied to the muscle is absorbed over a larger distance and longer period of time. This "cushioning effect" can reduce the trauma imposed on the muscle fibers and lower risk of injury 39,40 . This theory is supported by the findings of Watsford et al, who showed that Australian male football players who sustained a hamstring injury during the season had a significantly higher mean hamstring stiffness than non-injured players during pre-season testing ${ }^{40}$. Brockett et al found previously injured hamstrings had higher MTS compared to uninjured hamstrings, as measured by generating angletorque curves of the hamstring muscle, and concluded that an increase in MTS may be another factor contributing to the high re-injury rate of hamstring muscles ${ }^{41}$.

Two studies measured MTS by utilizing a mass spring system and observing the damping effect that the hamstring muscles imposed on oscillatory motion of the system ${ }^{38}$. Both found that women have a significantly lower MTS of hamstrings when compared to men ${ }^{38,42}$. Granata et al. also used a spring-mass oscillator model to calculate MTS of the lower limb muscles by recording vertical center of mass displacement and ground-reaction forces during a hopping task; women were again found to have lower MTS ${ }^{43}$. Female high school basketball athletes also showed significantly reduced hamstring stiffness compared to male athletes at three different degrees of hamstring flexion when MTS was measured via shear wave elastography, an ultrasound imaging technology that provides quantitative measurements of mechanical and elastic muscle tissue properties ${ }^{44}$. Given this association between MTS, sex differences and HSI, further studies are recommended to determine the specific role of MTS in the assessment and risk stratification for HSI in female athletes.

\section{Hamstring/Quadriceps Strength Ratio}

The hamstring to quadriceps strength ratio (H/Q ratio) is another well-studied and relevant physiological difference between men and women that may be a risk factor for HSI ${ }^{45-47}$. Yeung et al. found that a conventional H/Q ratio less than 0.6 increased HSI risk by 17 times when measured at $180^{\circ} / \mathrm{sec}$ in male and female sprinters ${ }^{45}$. A study of professional male soccer players found both conventional $\mathrm{H} / \mathrm{Q}$ ratio at $180^{\circ} / \mathrm{sec}$ and functional 
$\mathrm{H} / \mathrm{Q}$ ratio to be predictive of hamstring injury, when measured eccentrically at $30^{\circ} / \mathrm{sec}$ and concentrically at $240^{\circ} / \mathrm{sec}^{46}$. However, other studies have not confirmed this association in other populations ${ }^{48-51}$.

A systematic review and meta-analysis of 22 studies measuring conventional $\mathrm{H} / \mathrm{Q}$ ratios found males demonstrated statistically significantly greater $\mathrm{H} / \mathrm{Q}$ ratios than females at $60^{\circ} / \mathrm{s}, 120^{\circ} / \mathrm{s}, 300^{\circ} / \mathrm{s}$ and $360^{\circ} / \mathrm{s}^{52}$. Some authors suggest that the lower $\mathrm{H} / \mathrm{Q}$ ratio seen in females may be result of a sex discrepancy in hamstring strength and size rather than quadricep muscle differences 53,54 . Females are found to have 30\% smaller hamstring muscles than males while female quadricep muscles were only $25 \%$ smaller $^{54}$. After normalizing for body mass, Hannah et al. reported that men displayed a greater hamstring force production, but no difference in quadriceps force production when compared to women, resulting in a higher $\mathrm{H} / \mathrm{Q}$ ratio in men $^{53}$. The smaller $\mathrm{H} / \mathrm{Q}$ ratio in women has implications on knee joint stability and is thought to be a reason behind the increased incidence of ACL injuries in female athletes compared to male athletes, but has not yet been shown in relation to HSI ${ }^{15,54}$. Differences in H/Q ratios of males compared to females may also be influenced by the concept of limb dominance. Studies have found female athletes exhibit greater strength and kinematic asymmetries between their dominant and non-dominant lower limbs than male athletes ${ }^{55-57}$. This trend also extends to H/Q ratios. Female soccer players were found to have significantly lower conventional $\mathrm{H} / \mathrm{Q}$ ratios in their dominant leg compared to their non-dominant leg at all testing speeds ${ }^{58}$. Non-athlete females also demonstrate lower $\mathrm{H} / \mathrm{Q}$ ratios in their dominant leg59. However, similar studies in male athletes have shown either no difference in $H / Q$ ratio between dominant and non-dominant legs at multiple testing speeds, or increased $\mathrm{H} / \mathrm{Q}$ ratio in dominant legs at lower testing speeds ${ }^{60,61}$. In conclusion, females differ from males not only in the magnitude of their $\mathrm{H} / \mathrm{Q}$ ratio but also the degree of $\mathrm{H} / \mathrm{Q}$ ratio asymmetry between dominant and non-dominant limbs.

While the evidence of the relationship between $\mathrm{H} / \mathrm{Q}$ ratio and HSI occurrence is mixed and complicated by the multiple different methods used to measure $\mathrm{H} / \mathrm{Q}$ ratio, there may be a role for screening and prevention of HSI. Croisier et al. tested 687 professional male soccer players for lower limb strength imbalances (defined as a low $\mathrm{H} / \mathrm{Q}$ ratio or a difference in bilateral concentric or eccentric hamstring strength) during the preseason; players with imbalances were over 4 times more likely to sustain an HSI during the following season than players without preseason imbalances. Some players who were identified as having imbalances also received compensating training until isokinetic tests proved the imbalance was normalized; this group showed a significant reduction in HSI frequency compared to players with untreated imbalances $(5.7 \% \text { versus } 16.6 \%)^{47}$. While the direct association between $\mathrm{H} / \mathrm{Q}$ ratio on the risk of HSI in women remains unclear, further study that includes female athletes is needed to assess the role of preventative training for HSI.

Besides the H/Q ratio, other muscular activation and strength differences between men and women include that of the gluteal muscles. Vannatta and Kernozek found females produce lesser peak gluteus maximus forces and greater gluteus minimus, medius, and hamstring forces while running ${ }^{62}$. The authors note this may be a result of differing kinematics between the sexes, rather than ability of individual muscles, as females exhibit greater hip adduction and hip internal rotation while running ${ }^{62,63}$. A study of male soccer players found higher levels of gluteus maximus activity during sprinting resulted in a lower risk of $\mathrm{HSI}^{64}$. Another study reported an association between higher gluteus medius activation during running and hamstring injury in male Australian football players ${ }^{65}$. Taken together, these data may indicate the relative weakness of the gluteus maximus and relative strength of the other gluteal muscles can increase the risk of HSI in females. However, the small sample size of these respective studies and male-only cohorts warrants further investigation into this area.

\section{Skeletal Muscle Fatiguability}

Differences in female and male skeletal muscle fatigability during sprinting is another intrinsic difference that may contribute to the lower rate of HSI in female athletes. Females have been shown to be more resistant to skeletal muscle fatigue than men ${ }^{66-68}$. This is pertinent in the context of the HSI rate discrepancy between sexes as sprinting fatigue is thought to be a major risk factor for HSI ${ }^{8,69-72}$. The majority of HSIs occur during the latter stages of practices and competitions, with one study reporting that $47 \%$ of all hamstring injuries in 
professional soccer occur within the final $1 / 3^{\text {rd }}$ of each competition half 8,69 . The increased risk of injury has been proposed to be due to muscle fatigue impairing eccentric hamstring strength and the ability of the hamstring to absorb opposing force ${ }^{70-72}$. The eccentric hamstring strength of players has been shown to significantly decrease after performing exercises that simulate soccer match play ${ }^{70,71}$. Furthermore, Small et al. additionally found players experienced a reduced combined hip flexion and knee extension angle after the exercise, suggesting hamstring muscle length was shortened with fatigue ${ }^{73}$.

Several studies have shown that women are more resistant to skeletal muscle fatigue than men $^{66-68}$. Two studies, one in young adults and one in teenagers, found men experienced a greater sprint-induced mechanical work decrement than women when performing sprint repetitions separated by short periods of rest 67,68 . This occurred despite no sex differences in subjective effort perception ${ }^{67}$. Increased skeletal muscle endurance in women has also been observed in long-duration exercises $^{66}$. Temesi et al. found female runners displayed lower levels of peripheral fatigue in the plantar flexors and a smaller decrease in maximum torque of the knee flexors compared to male runners after completing an $100-\mathrm{km}$ ultramarathon ${ }^{66}$. The exact physiological mechanisms that contribute to women's enhanced endurance are still unknown, though differences in muscle metabolism, muscle contractile properties, vasodilatory response to exercise, and muscle fiber properties have been implicated ${ }^{74-78}$.

Billaut and Bishop suggested that the reason males are shown to fatigue earlier than women is because men have a greater initial power output and perform more mechanical work during exercises, and that this difference in performance is independent of sex-specific physiology ${ }^{79}$. The relationship between fatigue and female hamstring strength or kinematics has not been described in the literature and is an area for further study.

\section{Lower Limb Morphology}

Sex differences in lower extremity alignment and structural anatomy have been previously described and are thought to account for differences in rates of knee injury, but their influence on HSI rates have not been explored ${ }^{80-82}$. Women demonstrate between a 2.7 to $5.8^{\circ}$ greater quadriceps angle ( $\mathrm{Q}$ angle) than men when supine and between a $3.4^{\circ}$ to $4.9^{\circ}$ greater angle when standing 83 . A study in male futsal players has found a larger $Q$ angle may predispose one to increased hamstring tightness, which has been associated with risk for $\mathrm{HSI}^{84}$. Women are also shown to have $1.9^{\circ}$ to $4^{\circ}$ greater anterior pelvic tilt than men, which can increase the risk for HSI by elongating the hamstring musculotendinous unit and predisposing it to increased stress and strain $^{80,82,85,86}$. Schuermans et al. compared the running kinematics of soccer players with recent history of hamstring injuries to those of matched controls and found players with history of HSI displayed significantly more anterior pelvic tilting ${ }^{87}$. While these studies demonstrate a relationship between and HSI and lower limb alignment patterns that are greater in women, the lower rates of HSI in females suggest that the risk for HSIs is multifactorial.

Other sex-specific anatomic differences include the structure of the pelvis and the acetabular joint. The female pelvis is broader and exhibits an increased distance between the ischial tuberosities and ischial spines compared to males ${ }^{88-}$ 91. Females are also shown to have a greater suprapubic angle ${ }^{89}$. In the acetabular joint, females display a greater degree of both acetabular anteversion and femoral anteversion and have a smaller femoral head diameter ${ }^{92-95}$. Rates of developmental hip dysplasia are significantly higher in females, while rates of cam deformities are greater in male athletes ${ }^{96-98}$. These structural differences may impact lower limb and hip joint function in female athletes compared to males. Increased femoral anteversion can impair utilization of the vastus medialis and gluteus medius, while a smaller femoral head surface area and larger acetabular inner rim distance can increase contact stress in the hip joint ${ }^{95,99-103}$. However, the relationship of these anatomical differences to HSI is unclear. Further studies on specific morphological patterns within female athletes may be beneficial to identify the role of lower limb morphology on HSI.

\section{Conclusion}

Hamstring injuries are one of the most common injuries seen in all levels of sport and result in prolonged periods of time off while posing a significant risk of re-injury $4-11,13,14$. While rates of HSI are lower in women when compared to men, HSIs remain a frequent source of injury for female 
athletes ${ }^{18-20}$. There continues to be limited information about HSI when specifically comparing the difference in rates and risk factors between male and female athletes. The similar external risk factors for HSIs between men and women suggest the observed disparity may be a result of sex-based differences in intrinsic risk factors, such as increased flexibility, lower musculotendinous stiffness, and increased resistance to skeletal muscle fatigue in females as compared to their male counterparts ${ }^{22,23}$. The burden of HSIs in female athletes, as well as the sex-based differences in risk factors, suggest that effective hamstring injury rehabilitation and prevention may benefit from sexspecific programs. Further evidence is recommended to better understand and optimally manage hamstring injuries in the female athlete patient population.

\section{Conflict of Interest Statement}

The authors report no conflict of interest with the contents of this manuscript.

\section{Corresponding Author}

Miho J. Tanaka, MD, MA

Department of Orthopaedic Surgery

Massachusetts General Hospital

175 Cambridge St. Suite 400

Boston, Massachusetts 02114 USA

mtanaka5@mgh.harvard.edu

\section{REFERENCES}

1. Opar DA, Williams MD, Shield AJ. Hamstring Strain Injuries. Sports Med. 2012;42(3):209-226. doi:10.2165/11594800-000000000-00000

2. Goom TSH, Malliaras P, Reiman MP, Purdam CR. Proximal Hamstring Tendinopathy: Clinical Aspects of Assessment and Management. J Orthop Sports Phys Ther. 2016;46(6):483-493. doi:10.2519/jospt.2016.5986

3. Bylund WE, de Weber K. Semimembranosus Tendinopathy. Sports Health. 2010;2(5):380-384. doi:10.1177/1941738109357302

4. Hagel B. Hamstring injuries in Australian football. Clin J Sport Med. 2005;15(5):400. doi:10.1097/01.jsm.0000179227.01404.d3

5. Ekstrand J, Waldén M, Hägglund M. Hamstring injuries have increased by $4 \%$ annually in men's professional football, since 2001: a 13-year longitudinal analysis of the UEFA Elite Club injury study. $B r \quad J$ Sports Med. 2016;50(12):731-737. doi:10.1136/bjsports-2015-095359
6. Prior M, Guerin M, Grimmer K. An Evidence-Based Approach to Hamstring Strain Injury: A Systematic Review of the Literature. Sports Health. 2009;1(2):154164. doi:10.1177/1941738108324962

7. Askling C, Karlsson J, Thorstensson A. Hamstring injury occurrence in elite soccer players after preseason strength training with eccentric overload. Scand J Med Sci Sports. 2003;13(4):244-250. doi:10.1034/j.1600-0838.2003.00312.x

8. Roe M, Murphy JC, Gissane C, Blake C. Hamstring injuries in elite Gaelic football: an 8-year investigation to identify injury rates, time-loss patterns and players at increased risk. $\mathrm{Br} J$ Sports Med. 2018;52(15):982-988. doi:10.1136/bjsports-2016096401

9. Woods C, Hawkins RD, Maltby S, Hulse M, Thomas A, Hodson A. The Football Association Medical Research Programme: an audit of injuries in professional football - analysis of hamstring injuries. British Journal of Sports Medicine. 2004;38(1):36-41. doi:10.1136/bjsm.2002.002352

10. Ekstrand J, Gillquist J. The frequency of muscle tightness and injuries in soccer players. Am J Sports Med. 1982;10(2):75-78. doi:10.1177/036354658201000202

11. Mack CD, Kent RW, Coughlin MJ, et al. Incidence of Lower Extremity Injury in the National Football League: 2015 to 2018. Am J Sports Med. 2020;48(9):2287-2294. doi:10.1177/0363546520922547

12. Hamstring muscle injuries in professional football: the correlation of MRI findings with return to play | British Journal of Sports Medicine. Accessed April 16, 2021. https://bjsm.bmj.com/content/46/2/112

13. Malliaropoulos N, Papacostas E, Kiritsi O, et al. Posterior Thigh Muscle Injuries in Elite Track and Field Athletes. Am J Sports Med. 2010;38(9):1813-1819. doi:10.1177/0363546510366423

14. Green B, Bourne MN, Dyk $N$ van, Pizzari $T$. Recalibrating the risk of hamstring strain injury (HSI): A 2020 systematic review and meta-analysis of risk factors for index and recurrent hamstring strain injury in sport. Br J Sports Med. 2020;54(18):1081-1088. doi:10.1136/bjsports-2019-100983

15. Prodromos CC, Han Y, Rogowski J, Joyce B, Shi K. A meta-analysis of the incidence of anterior cruciate ligament tears as a function of gender, sport, and a knee injury-reduction regimen. Arthroscopy. 2007;23(12):1320-1325.e6. doi:10.1016/j.arthro.2007.07.003

16. The Challenge of Applying and Undertaking Research in Female Sport | Sports Medicine - Open | Full Text. Accessed April 16, 2021. https://sportsmedicineopen.springeropen.com/articles/10.1186/s40798019-0224-x

17. Costello JT, Bieuzen F, Bleakley CM. Where are all the female participants in Sports and Exercise 
Medicine research? Eur J Sport Sci. 2014;14(8):847851. doi:10.1080/17461391.2014.911354

18. O'Connor S, Bruce C, Teahan C, McDermott E, Whyte E. Injuries in Collegiate Ladies Gaelic Footballers: A 2-Season Prospective Cohort Study. J Sport Rehabil. Published online May 29, 2020:1-6. doi:10.1123/jsr.2019-0468

19. Crossley KM, Patterson BE, Culvenor AG, Bruder AM, Mosler AB, Mentiplay BF. Making football safer for women: a systematic review and meta-analysis of injury prevention programmes in 11773 female football (soccer) players. $\mathrm{Br} J$ Sports Med. 2020;54(18):1089-1098. doi:10.1136/bjsports-2019101587

20. Söderman K, Alfredson H, Pietilä T, Werner S. Risk factors for leg injuries in female soccer players: a prospective investigation during one out-door season. Knee Surg Sports Traumatol Art. 2001;9(5):313321. doi:10.1007/s001670100228

21. Dalton SL, Kerr ZY, Dompier TP. Epidemiology of Hamstring Strains in 25 NCAA Sports in the 20092010 to 2013-2014 Academic Years. Am J Sports Med. 2015;43(11):2671-2679. doi:10.1177/0363546515599631

22. Cross KM, Gurka KK, Saliba S, Conaway M, Hertel J. Comparison of hamstring strain injury rates between male and female intercollegiate soccer athletes. Am J Sports Med. 2013;41(4):742-748. doi:10.1177/0363546513475342

23. Edouard P, Branco P, Alonso J-M. Muscle injury is the principal injury type and hamstring muscle injury is the first injury diagnosis during top-level international athletics championships between 2007 and 2015. Br J Sports Med. 2016;50(10):619-630. doi:10.1136/bjsports-2015-095559

24. Alonso J-M, Edouard P, Fischetto G, Adams B, Depiesse F, Mountjoy M. Determination of future prevention strategies in elite track and field: analysis of Daegu 2011 IAAF Championships injuries and illnesses surveillance. Br J Sports Med. 2012;46(7):505514. doi:10.1136/bjsports-2012-091008

25. Larruskain J, Lekue JA, Diaz N, Odriozola A, Gil SM. A comparison of injuries in elite male and female football players: A five-season prospective study. Scandinavian Journal of Medicine $\mathcal{E}$ Science in Sports. 2018;28(1):237-245.

doi:https://doi.org/10.1111/sms.12860

26. Wan X, Qu F, Garrett WE, Liu H, Yu B. The effect of hamstring flexibility on peak hamstring muscle strain in sprinting. Journal of Sport and Health Science. 2017;6(3):283-289. doi:10.1016/j.jshs.2017.03.012

27. Witvrouw E, Danneels L, Asselman P, D'Have T, Cambier D. Muscle Flexibility as a Risk Factor for Developing Muscle Injuries in Male Professional Soccer Players: A Prospective Study. Am J Sports Med. 2003;31(1):41-46. doi:10.1177/03635465030310011801
28. Henderson G, Barnes CA, Portas MD. Factors associated with increased propensity for hamstring injury in English Premier League soccer players. Journal of Science and Medicine in Sport. 2010;13(4):397402. doi:10.1016/j.jsams.2009.08.003

29. Bradley PS, Portas MD. The relationship between preseason range of motion and muscle strain injury in elite soccer players. I Strength Cond Res. 2007;21(4):1155-1159. doi:10.1519/R-20416.1

30. Marshall PWM, Siegler JC. Lower hamstring extensibility in men compared to women is explained by differences in stretch tolerance. $B M C$ Musculoskelet Disord. 2014;15:223. doi:10.1186/14712474-15-223

31. Youdas JW, Krause DA, Hollman JH, Harmsen WS, Laskowski E. The influence of gender and age on hamstring muscle length in healthy adults. J Orthop Sports Phys Ther. 2005;35(4):246-252. doi:10.2519/jospt.2005.35.4.246

32. van Doormaal MCM, van der Horst N, Backx FJG, Smits D-W, Huisstede BMA. No Relationship Between Hamstring Flexibility and Hamstring Injuries in Male Amateur Soccer Players: A Prospective Study. Am J Sports Med. 2017;45(1):121126. doi: $10.1177 / 0363546516664162$

33. O'Connor S, McCaffrey N, Whyte EF, Fop M, Murphy B, Moran KA. Is Poor Hamstring Flexibility a Risk Factor for Hamstring Injury in Gaelic Games? J Sport Rehabil. 2019;28(7):677-681. doi:10.1123/jsr.2017-0304

34. Rolls A, George K. The relationship between hamstring muscle injuries and hamstring muscle length in young elite footballers. Physical Therapy in Sport. doi:10.1016/j.ptsp.2004.08.005

35. Gabbe BJ, Bennell KL, Finch CF, Wajswelner $\mathrm{H}$, Orchard JW. Predictors of hamstring injury at the elite level of Australian football. Scandinavian Journal of Medicine $\mathcal{E}$ Science in Sports. 2006;16(1):7-13. doi:https://doi.org/10.1111/j.16000838.2005.00441.x

36. Engebretsen AH, Myklebust G, Holme I, Engebretsen L, Bahr R. Intrinsic risk factors for hamstring injuries among male soccer players: a prospective cohort study. Am J Sports Med. 2010;38(6):1147-1153. doi:10.1177/0363546509358381

37. Bennell K, Tully E, Harvey N. Does the toe-touch test predict hamstring injury in Australian Rules footballers? Aust J Physiother. 1999;45(2):103-109. doi:10.1016/s0004-9514(14)60342-1

38. Blackburn JT, Riemann BL, Padua DA, Guskiewicz KM. Sex comparison of extensibility, passive, and active stiffness of the knee flexors. Clin Biomech (Bristol, Avon). 2004;19(1):36-43. doi:10.1016/j.clinbiomech.2003.09.003

39. Wilson GJ, Wood GA, Elliott BC. The Relationship between Stiffness of the Musculature and Static 
Flexibility: An Alternative Explanation for the Occurrence of Muscular Injury. Int J Sports Med. 1991;12(04):403-407. doi:10.1055/s-2007-1024702

40. A Prospective Study of the Relationship between Lower Body Stiffness and Hamstring Injury in Professional Australian Rules Footballers - Mark L. Watsford, Aron J. Murphy, Ken A. McLachlan, Adam L. Bryant, Matt L. Cameron, Kay M. Crossley, Michael Makdissi, 2010. Accessed April 17, 2021. https://journals.sagepub.com/doi/10.1177/036354 6510370197

41. Brockett CL, Morgan DL, Proske U. Predicting hamstring strain injury in elite athletes. Med Sci Sports Exerc. 2004;36(3):379-387. doi:10.1249/01.mss.0000117165.75832.05

42. Blackburn JT, Bell DR, Norcross MF, Hudson JD, Engstrom LA. Comparison of hamstring neuromechanical properties between healthy males and females and the influence of musculotendinous stiffness. J Electromyogr Kinesiol. 2009;19(5):e362-369. doi:10.1016/j.jelekin.2008.08.005

43. Granata KP, Padua DA, Wilson SE. Gender differences in active musculoskeletal stiffness. Part II. Quantification of leg stiffness during functional hopping tasks. J Electromyogr Kinesiol. 2002;12(2):127135. doi:10.1016/s1050-6411(02)00003-2

44. McPherson AL, Nagai T, Schilaty ND, Hale R, Hewett TE, Bates NA. High school male basketball athletes exhibit greater hamstring muscle stiffness than females as assessed with shear wave elastography. Skeletal Radiol. 2020;49(8):1231-1237. doi:10.1007/s00256-020-03397-w

45. Yeung SS, Suen AMY, Yeung EW. A prospective cohort study of hamstring injuries in competitive sprinters: preseason muscle imbalance as a possible risk factor. British Journal of Sports Medicine. 2009;43(8):589-594. doi:10.1136/bjsm.2008.056283

46. Dauty M, Menu P, Fouasson-Chailloux A, Ferréol S, Dubois C. Prediction of hamstring injury in professional soccer players by isokinetic measurements. Muscles Ligaments Tendons J. 2016;6(1):116-123. doi:10.11138/mltj/2016.6.1.116

47. Croisier J-L, Ganteaume S, Binet J, Genty M, Ferret JM. Strength Imbalances and Prevention of Hamstring Injury in Professional Soccer Players: A Prospective Study. Am J Sports Med. 2008;36(8):14691475. doi:10.1177/0363546508316764

48. Freckleton G, Pizzari T. Risk factors for hamstring muscle strain injury in sport: a systematic review and meta-analysis. Br J Sports Med. 2013;47(6):351-358. doi:10.1136/bjsports-2011-090664

49. van Dyk N, Bahr R, Whiteley R, et al. Hamstring and Quadriceps Isokinetic Strength Deficits Are Weak Risk Factors for Hamstring Strain Injuries: A 4-Year Cohort Study. Am J Sports Med. 2016;44(7):1789-1795. doi:10.1177/0363546516632526
50. Bennell $\mathrm{K}$, Wajswelner $\mathrm{H}$, Lew $\mathrm{P}$, et al. Isokinetic strength testing does not predict hamstring injury in Australian Rules footballers. British Journal of Sports Medicine. doi:10.1136/bjsm.32.4.309

1998;32(4):309-314.

51. Zvijac JE, Toriscelli TA, Merrick S, Kiebzak GM. Isokinetic Concentric Quadriceps and Hamstring Strength Variables From the NFL Scouting Combine Are Not Predictive of Hamstring Injury in First-Year Professional Football Players. Am J Sports Med. 2013;41(7):1511-1518. doi:10.1177/0363546513487983

52. Hewett TE, Myer GD, Zazulak BT. Hamstrings to quadriceps peak torque ratios diverge between sexes with increasing isokinetic angular velocity. J Sci Med Sport. doi:10.1016/j.jsams.2007.04.009

2008;11(5):452-459.

53. Hannah R, Folland JP, Smith SL, Minshull C. Explosive hamstrings-to-quadriceps force ratio of males versus females. Eur J Appl Physiol. 2015;115(4):837-847. doi:10.1007/s00421-014-3063-y

54. Behan FP, Maden-Wilkinson TM, Pain MTG, Folland JP. Sex differences in muscle morphology of the knee flexors and knee extensors. PLoS One. 2018;13(1). doi:10.1371/journal.pone.0190903

55. Weinhandl JT, Irmischer BS, Sievert ZA, Fontenot $\mathrm{KC}$. Influence of sex and limb dominance on lower extremity joint mechanics during unilateral landand-cut manoeuvres. J Sports Sci. 2017;35(2):166-174. doi:10.1080/02640414.2016.1159716

56. Hewett TE, Myer GD, Ford KR. Anterior Cruciate Ligament Injuries in Female Athletes: Part 1, Mechanisms and Risk Factors. Am J Sports Med. 2006;34(2):299-311. doi:10.1177/0363546505284183

57. Owens EM, Serrano AJ, Ramsey MW, Mizuguchi S, Johnston B, Stone MH. Comparing Lower-Limb Asymmetries in NCAA D-I Male and Female Athletes. The Journal of Strength $\mathcal{E}$ Conditioning Research. 2011;25:S44. doi:10.1097/01.JSC.0000395647.08972.ca

58. Holcomb WR, Rubley MD, Lee HJ, Guadagnoli MA. Effect of Hamstring-Emphasized Resistance Training on Hamstring:quadriceps Strength Ratios. Journal of Strength and Conditioning Research. 2007;21(1):41-47. doi:http:/ / dx.doi.org/10.1519/00124278-20070200000008

59. Lanshammar K, Ribom EL. Differences in muscle strength in dominant and non-dominant leg in females aged 20-39 years - A population-based study. Physical Therapy in Sport. 2011;12(2):76-79. doi:10.1016/j.ptsp.2010.10.004

60. Cheung RTH, Smith AW, Wong DP. H:Q Ratios and Bilateral Leg Strength in College Field and Court Sports Players. J Hum Kinet. 2012;33:63-71. doi:10.2478/v10078-012-0045-1

61. Magalhães J, Oliveira J, Ascensão A, Soares J. Concentric quadriceps and hamstrings isokinetic 
strength in volleyball and soccer players. The Journal of sports medicine and physical fitness. 2004;44:119-125.

62. Vannatta CN, Kernozek TW. Sex differences in gluteal muscle forces during running. Sports Biomechanics. 2021;20(3):319-329. doi:10.1080/14763141.2018.1548641

63. Ferber R, Davis IM, Williams DS. Gender differences in lower extremity mechanics during running. Clin Biomech (Bristol, Avon). 2003;18(4):350-357. doi:10.1016/s0268-0033(03)00025-1

64. Schuermans J, Danneels L, Van Tiggelen D, Palmans T, Witvrouw E. Proximal Neuromuscular Control Protects Against Hamstring Injuries in Male Soccer Players: A Prospective Study With Electromyography Time-Series Analysis During Maximal Sprinting. Am J Sports Med. 2017;45(6):13151325. doi:10.1177/0363546516687750

65. Franettovich Smith MM, Bonacci J, Mendis MD, Christie C, Rotstein A, Hides JA. Gluteus medius activation during running is a risk factor for season hamstring injuries in elite footballers. Journal of Science and Medicine in Sport. 2017;20(2):159-163. doi:10.1016/j.jsams.2016.07.004

66. Temesi J, Arnal PJ, Rupp T, et al. Are Females More Resistant to Extreme Neuromuscular Fatigue? Med Sci Sports Exerc. 2015;47(7):1372-1382. doi:10.1249/MSS.0000000000000540

67. Billaut FB, Smith KS. Sex alters impact of repeated bouts of sprint exercise on neuromuscular activity in trained athletes. Applied Physiology, Nutrition, and Metabolism. Published online August 7, 2009. doi:10.1139/H09-058

68. Yanagiya T, Kanehisa H, Kouzaki M, Kawakami Y, Fukunaga T. Effect of gender on mechanical power output during repeated bouts of maximal running in trained teenagers. Int J Sports Med. 2003;24(4):304310. doi:10.1055/s-2003-39508

69. Brooks JHM, Fuller CW, Kemp SPT, Reddin DB. Incidence, risk, and prevention of hamstring muscle injuries in professional rugby union. Am J Sports Med. 2006;34(8):1297-1306. doi:10.1177/0363546505286022

70. Small K, McNaughton L, Greig M, Lovell R. The effects of multidirectional soccer-specific fatigue on markers of hamstring injury risk. Journal of Science and Medicine in Sport. 2010;13(1):120-125. doi:10.1016/j.jsams.2008.08.005

71. Greig M. The influence of soccer-specific fatigue on peak isokinetic torque production of the knee flexors and extensors. Am J Sports Med. 2008;36(7):1403-1409. doi:10.1177/0363546508314413

72. Wing C, Bishop C. Hamstring Strain Injuries: Incidence, Mechanisms, Risk Factors, and Training Recommendations. Strength $\mathcal{E}$ Conditioning Journal. 2020;42(3):40-57. doi:10.1519/SSC.0000000000000538

73. Small K, McNaughton LR, Greig M, Lohkamp M, Lovell R. Soccer fatigue, sprinting and hamstring injury risk. Int J Sports Med. 2009;30(8):573-578. doi:10.1055/s-0029-1202822

74. Simoneau JA, Bouchard C. Human variation in skeletal muscle fiber-type proportion and enzyme activities. Am J Physiol. 1989;257(4 Pt 1):E567-572. doi:10.1152/ajpendo.1989.257.4.E567

75. Carter SL, Rennie CD, Hamilton SJ, Tarnopolsky null. Changes in skeletal muscle in males and females following endurance training. Can J Physiol Pharmacol. 2001;79(5):386-392.

76. Herbison GJ, Jaweed MM, Ditunno JF. Muscle fiber types. Arch Phys Med Rehabil. 1982;63(5):227-230.

77. Hunter SK. Sex differences in human fatigability: mechanisms and insight to physiological responses. Acta Physiol (Oxf). 2014;210(4):768-789. doi:10.1111/apha.12234

78. Clark BC, Collier SR, Manini TM, Ploutz-Snyder LL. Sex differences in muscle fatigability and activation patterns of the human quadriceps femoris. Eur J Appl Physiol. 2005;94(1-2):196-206. doi:10.1007/s00421004-1293-0

79. Billaut F, Bishop D. Muscle fatigue in males and females during multiple-sprint exercise. Sports Med. 2009;39(4):257-278. doi:10.2165/00007256-20093904000001

80. Medina McKeon JM, Hertel J. Sex Differences and Representative Values for 6 Lower Extremity Alignment Measures. J Athl Train. 2009;44(3):249-255.

81. Tillman MD, Bauer JA, Cauraugh JH, Trimble MH. Differences in lower extremity alignment between males and females. Potential predisposing factors for knee injury. J Sports Med Phys Fitness. 2005;45(3):355359.

82. Nguyen A-D, Shultz SJ. Sex differences in clinical measures of lower extremity alignment. J Orthop Sports Phys Ther. 2007;37(7):389-398. doi:10.2519/jospt.2007.2487

83. Livingston LA. The quadriceps angle: a review of the literature. J Orthop Sports Phys Ther. 1998;28(2):105109. doi:10.2519/jospt.1998.28.2.105

84. Minoonejad H, Tasoujian E, Amiri H, Manteghi R. Comparison of Q Angle and Tibial Torsion Among Premier League Futsal Players With and Without Hamstring Tightness. Physical Treatments - Specific Physical Therapy Journal. 2016;6(1):51-58. doi:10.18869/nrip.ptj.6.1.51

85. Cibulka MT, Rose SJ, Delitto A, Sinacore DR. Hamstring muscle strain treated by mobilizing the sacroiliac joint. Phys Ther. 1986;66(8):1220-1223. doi:10.1093/ptj/66.8.1220

86. Carlson $\mathrm{C}$. The natural history and management of hamstring injuries. Curr Rev Musculoskelet Med. 2008;1(2):120-123. doi:10.1007/s12178-007-9018-8

87. Schuermans J, Van Tiggelen D, Palmans T, Danneels L, Witvrouw E. Deviating running kinematics and hamstring injury susceptibility in male soccer 
players: Cause or consequence? Gait Posture. 2017;57:270-277. doi:10.1016/j.gaitpost.2017.06.268

88. Huseynov A, Zollikofer CPE, Coudyzer W, et al. Developmental evidence for obstetric adaptation of the human female pelvis. Proc Natl Acad Sci USA. 2016;113(19):5227-5232. doi:10.1073/pnas.1517085113

89. Young $\mathrm{M}$, Ince JGH. A radiographic comparison of the male and female pelvis. J Anat. 1940;74(Pt 3):374385.

90. Wang SC, Brede C, Lange D, et al. Gender Differences in Hip Anatomy: Possible Implications for Injury Tolerance in Frontal Collisions. Annu Proc Assoc Adv Automot Med. 2004;48:287-301.

91. Nwoha PU. The anterior dimensions of the pelvis in male and female Nigerians. Afr J Med Med Sci. 1995;24(4):329-335.

92. Nakahara I, Takao M, Sakai T, Nishii T, Yoshikawa H, Sugano N. The Gender Difference of Normal Hip Joint Anatomy. :1.

93. Nakahara I, Takao M, Sakai T, Nishii T, Yoshikawa $\mathrm{H}$, Sugano N. Gender differences in 3D morphology and bony impingement of human hips. Journal of Orthopaedic Research. 2011;29(3):333-339. doi:10.1002/jor.21265

94. Atkinson HD, Johal KS, Willis-Owen C, Zadow S, Oakeshott RD. Differences in hip morphology between the sexes in patients undergoing hip resurfacing. J Orthop Surg Res. 2010;5:76. doi:10.1186/1749-799X-5-76

95. Brinckmann $P$, Hoefert $H$, Jongen HTh. Sex differences in the skeletal geometry of the human pelvis and hip joint. Journal of Biomechanics. 1981;14(6):427-430. doi:10.1016/0021-9290(81)900609

96. Gerhardt MB, Romero AA, Silvers HJ, Harris DJ, Watanabe D, Mandelbaum BR. The Prevalence of Radiographic Hip Abnormalities in Elite Soccer Players. Am J Sports Med. 2012;40(3):584-588. doi: $10.1177 / 0363546511432711$
97. Johnson AC, Shaman MA, Ryan TG. Femoroacetabular impingement in former high-level youth soccer players. Am J Sports Med. 2012;40(6):1342-1346. doi:10.1177/0363546512439287

98. Loder RT, Skopelja EN. The Epidemiology and Demographics of Hip Dysplasia. ISRN Orthop. 2011;2011:238607. doi:10.5402/2011/238607

99. Kersnič B, Iglič A, Kralj-Iglič V, et al. Determination of the femoral and pelvic geometrical parameters that are important for the hip joint contact stress: Differences between female and male. Pflugers Arch. 1996;431(S6):R207-R208. doi:10.1007/BF02346341

100. Brinckmann P, Frobin W, Hierholzer E. Stress on the articular surface of the hip joint in healthy adults and persons with idiopathic osteoarthrosis of the hip joint. Journal of Biomechanics. 1981;14(3):149-156. doi:10.1016/0021-9290(81)90021-X

101. Kaneko M, Sakuraba K. Association between Femoral Anteversion and Lower Extremity Posture upon Single-leg Landing: Implications for Anterior Cruciate Ligament Injury. I Phys Ther Sci. 2013;25(10):1213-1217. doi:10.1589/jpts.25.1213

102. Nyland J, Kuzemchek S, Parks M, Caborn DNM. Femoral anteversion influences vastus medialis and gluteus medius EMG amplitude: composite hip abductor EMG amplitude ratios during isometric combined hip abduction-external rotation. Journal of Electromyography and Kinesiology. 2004;14(2):255-261. doi:10.1016/S1050-6411(03)00078-6

103. Magnetic Resonance Imaging Analysis of Rotational Alignment in Patients With Patellar Dislocations - Gerd Diederichs, Torsten Köhlitz, Evgenios Kornaropoulos, Markus O. Heller, Bernd Vollnberg, Sven Scheffler, 2013. Accessed July 5, 2021.

https://journals.sagepub.com/doi/10.1177/036354 6512464691 